\title{
Stratospheric water vapour and high climate sensitivity in a version of the HadSM3 climate model
}

\author{
M. M. Joshi ${ }^{1}$, M. J. Webb ${ }^{2}$, A. C. Maycock ${ }^{3}$, and M. Collins ${ }^{4}$ \\ ${ }^{1}$ National Centre for Atmospheric Science (NCAS) Climate, University of Reading, Earley Gate, Reading RG6 6BB, UK \\ ${ }^{2}$ Met Office Hadley Centre, FitzRoy Road, Exeter EX1 3PB, UK \\ ${ }^{3}$ Department of Meteorology, University of Reading, Earley Gate, Reading RG6 6BB, UK \\ ${ }^{4}$ College of Engineering, Mathematics and Physical Sciences, University of Exeter, North Park Road, Exeter EX4 4QF, UK
}

Received: 22 January 2010 - Published in Atmos. Chem. Phys. Discuss.: 5 March 2010

Revised: 19 July 2010 - Accepted: 25 July 2010 - Published: 4 August 2010

\begin{abstract}
It has been shown previously that one member of the Met Office Hadley Centre single-parameter perturbed physics ensemble - the so-called "low entrainment parameter" member - has a much higher climate sensitivity than other individual parameter perturbations. Here we show that the concentration of stratospheric water vapour in this member is over three times higher than observations, and, more importantly for climate sensitivity, increases significantly when climate warms. The large surface temperature response of this ensemble member is more consistent with stratospheric humidity change, rather than upper tropospheric clouds as has been previously suggested. The direct relationship between the bias in the control state (elevated stratospheric humidity) and the cause of the high climate sensitivity (a further increase in stratospheric humidity) lends further doubt as to the realism of this particular integration. This, together with other evidence, lowers the likelihood that the climate system's physical sensitivity is significantly higher than the likely upper range quoted in the Intergovernmental Panel on Climate Change's Fourth Assessment Report.
\end{abstract}

\section{Introduction}

Much discussion has centred on the likelihood of the sensitivity of the physical climate system being significantly larger than the $2-4.5 \mathrm{~K}$ range quoted in the Intergovernmental Panel on Climate Change (IPCC)'s Fourth Assessment

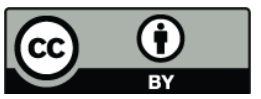

Correspondence to: M. M. Joshi

(m.m.joshi@ reading.ac.uk)
Report (AR4) (IPCC, 2007). The upper bound is sensitive to how model parameters are sampled and to the method used to compare with observations (e.g.: see section 10.5.1 of Meehl et al., 2007).

The Quantifying Uncertainty in Model Prediction (QUMP) ensemble (Murphy et al., 2004) consisted of a series of general circulation model or GCM integrations with different perturbed parameters designed to sample uncertainties in physical processes. The integration that is the subject of this paper is the so-called low entrainment parameter (henceforth LEP) integration, carried out with the Met Office Hadley Centre's HadSM3 climate model. When entrainment rates in the model's convection scheme are set to low values, the climate sensitivity is approximately $7 \mathrm{~K}$ on doubling $\mathrm{CO}_{2}$ from pre-industrial values, which is much higher than the IPCC range of $2-4.5 \mathrm{~K}$ quoted above, and much higher than any other member of the single-parameter Murphy et al. (2004) ensemble.

It is clearly important to assess the validity of the LEP run, given that such a high sensitivity would have profound implications for climate change in the latter half of the 21st century and beyond, given current emissions projections, and an equivalently profound impact on international negotiations to limit emissions. Some limited evaluation is presented in Collins et al. (2010) in the form of global bias and rootmean-squared error statistics for a number of different $2 \mathrm{~d}$ time-averaged climatologies (their Fig. 2). In the ensemble considered here where just one model parameter is perturbed at a time (labelled S-PPE-S in Collins et al., 2010) the performance of the low entrainment is competitive with other members of the ensemble. It could certainly not be described as an outlier. In addition, the spread of global mean biases and the magnitude of RMS errors are both smaller in this

Published by Copernicus Publications on behalf of the European Geosciences Union. 
ensemble than they are in the CMIP3/CFMIP multi-model ensemble of slab experiments. Here we focus on one aspect of the LEP run: its high stratospheric humidity, and the implications of changes in this quantity for the validity of the LEP run, and the feedback processes occurring in it.

Elevated values of humidity in the upper tropospheric/lower stratospheric (UTLS) region in lowentrainment-parameter HadSM3 experiments have been noticed before by Sanderson et al. (2008). They found relative humidity (RH) changed by $30 \%$ on doubling $\mathrm{CO}_{2}$ in a version of the LEP run carried out by the Climateprediction.net project (Stainforth et al., 2005). They inferred that high cloud in the UTLS region was responsible for the high sensitivity. However, their Fig. 7 shows high values of RH in the tropics at the $20-25 \mathrm{~km}$ level compared to a control simulation, which is not only at a much higher altitude than the cold point of the tropical tropopause, but also insufficient to cause cloud formation in such a dry region. This study explores an alternative interpretation that stratospheric water vapour (henceforth SWV) changes rather than cloud changes are the main cause of the high climate sensitivity of the LEP run.

In a standard HadSM3 simulation, water vapour is freeze dried as it reaches the coldest point of the tropical tropopause; this leads to very low values of SWV of approximately 2-3 ppmv, consistent with observations. Here we show that high values of SWV occur in the LEP run because less entrainment in convection reduces the dilution of convective plumes by dry air. The plumes are therefore more intense, and cause the upper tropical troposphere to moisten far more than in the standard simulation. The moister air is then available for transport from the upper troposphere into the lower stratosphere isentropically in the subtropics, where the tropopause height changes rapidly, and isentropes cross the tropopause. We note that such transport has been previously identified in a predecessor to HadSM3, called HadCM2, which had similar dynamics (D. Karoly, personal communication, 2009).

In this paper we show that SWV biases in the LEP run are far worse than suggested by Sanderson et al. (2008), and cast doubt on this aspect of the plausibility of this ensemble member's climatology. We then show that the extra radiative effect associated with the stratospheric moisture change in the $2 \times \mathrm{CO}_{2} \mathrm{LEP}$ integration is almost as large as the $\mathrm{CO}_{2}$ forcing itself, and can explain the high climate sensitivity of LEP. We also rule out cloud changes as a substantial contributor to the differences in sensitivity between the LEP and the standard version of HadSM3. We then discuss our results in the context of constraining climate sensitivity.

\section{Results}

We present results from four integrations of the HadSM3 model: a standard-parameter control run and an LEP run with pre-industrial $\mathrm{CO}_{2}$ (STD1 and LEP1 respectively) as well as
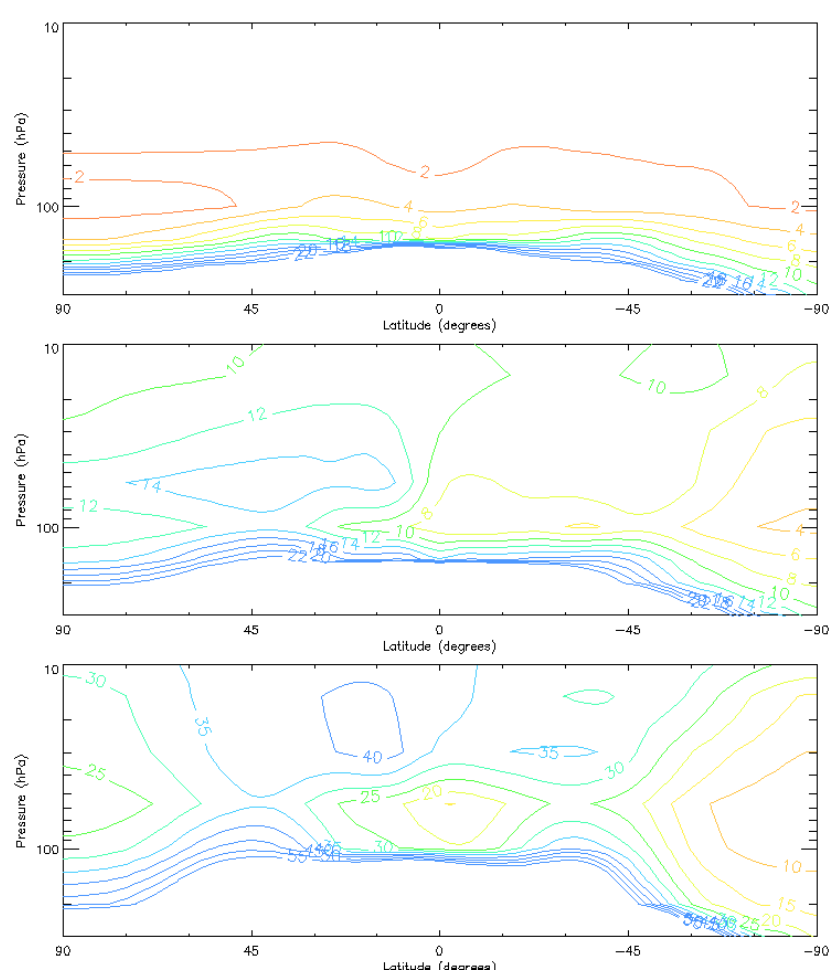

Fig. 1. Time averaged zonal-mean cross sections of specific humidity in ppmv in the standard-parameter version of HadSM3 with preindustrial $\mathrm{CO}_{2}$ levels-STD1 (top), the low-entrainment perturbed version of HadSM3 with pre-industrial $\mathrm{CO}_{2}$-LEP1 (middle) and the low-entrainment perturbed version under a doubling of $\mathrm{CO}_{2}$-LEP2 (bottom). Note the different contour intervals in the two plots $(2,2$, and 5 ppmv respectively).

a standard-parameter and a LEP run with $2 \times$ pre-industrial $\mathrm{CO}_{2}$ (STD2 and LEP2 respectively). The LEP2 run was started from the STD2 $2 \times \mathrm{CO}_{2}$ state, which has implications for some of the interpretation later.

Figure 1 (top panel) shows SWV in STD1 in the stratosphere; values of specific humidity are broadly consistent with observations, though slightly smaller than recently observed values (e.g.: Rosenlof et al., 2001). The difference between STD1 and STD2 under enhanced $\mathrm{CO}_{2}$ is small (less than 0.5 ppmv, not shown). Figure 1 (middle) shows that SWV in LEP1 is much higher than in STD1. The large hemispheric asymmetry also appears inconsistent with observations. Sanderson et al. (2008) suggested that the differences between LEP1 and STD1 are concentrated in the UTLS region, but Fig. 1 (middle) exhibits large differences throughout the stratospheres of the different model versions. We suggest that the reason for their interpretation is that they diagnosed differences in RH rather than specific humidity $q$ : the choice of the former magnifies differences where RH is large, i.e. near the cold point of the tropical tropopause at the $100 \mathrm{hPa}$ level. Consider, for example, two levels having similar values of $q$, but $\mathrm{RH}$ values of $1 \%$ and $25 \%$, representing 

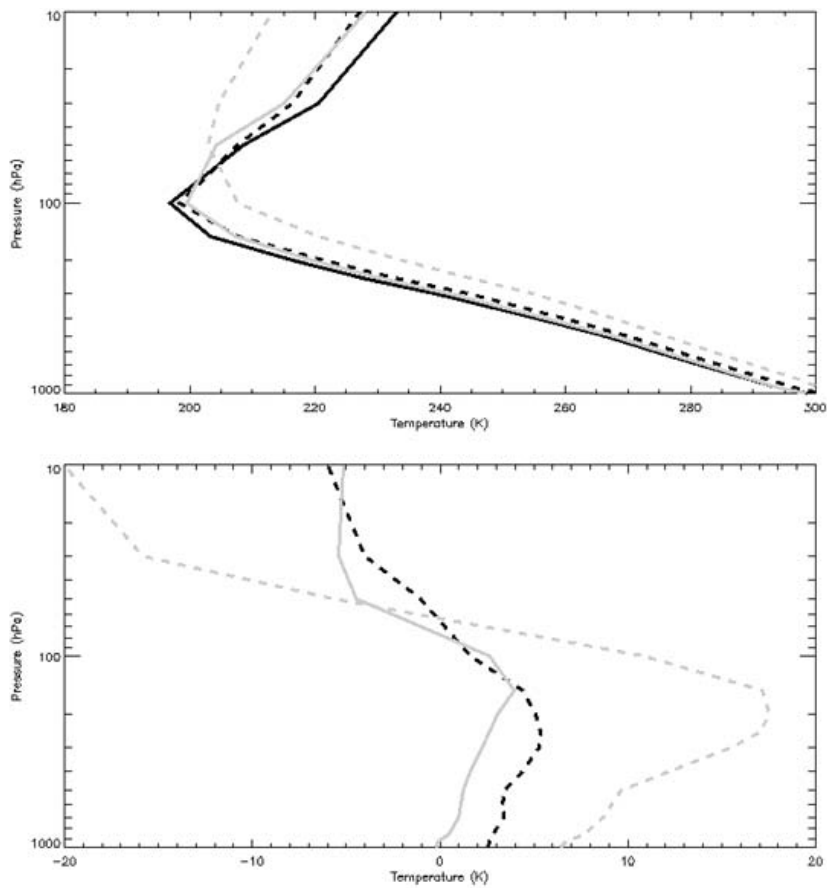

Fig. 2. Top panel: time-mean global-average vertical temperature profiles for STD1 (solid black); STD2 (dashed black); LEP1 (solid grey) and LEP2 (dashed grey); bottom panel: STD2 minus STD1 (dashed black); LEP1 minus STD1 (solid grey) and LEP2 minus STD1 (dashed grey).

the mid-stratosphere and tropopause respectively. If specific humidity is doubled at both levels, the former will exhibit a change in $\mathrm{RH}$ of $1 \%$, whereas the latter will show a change of $25 \%$ which under-emphasizes the mid-stratospheric change.

LEP2 (Fig. 1 bottom panel) has SWV values approaching $40 \mathrm{ppmv}$ in the mid-stratosphere, which is an order of magnitude higher than present-day observations. LEP2 exhibits positive anomalies in the subtropics, where the tropopause drops in height, and isentropes cross it. These anomalies are consistent with humid air in LEP2 being isentropicallytransported polewards from the upper troposphere into the lower stratosphere, and being uplifted in the Brewer-Dobson circulation. Additionally, SWV at the equator at $50-100 \mathrm{hPa}$ is a factor of 1.5-2 lower than elsewhere in the lower stratosphere, which also suggests that tropical cold-point temperature is not the main factor controlling stratospheric humidity in LEP2, as it is in reality.

Tropical temperature profiles are shown in Fig. 2 (top). STD1, STD2, and LEP1 all reach minima at approximately $100 \mathrm{hPa}$, and have minima between $195 \mathrm{~K}$ and $200 \mathrm{~K}$, in line with observations. The reason for STD1 and STD2 having similar tropopause heights in spite of the equilibrium warming is most likely the coarse resolution of HadCM3, which is approximately $3 \mathrm{~km}$ at the tropopause. LEP 2 has a higher tropopause, consistent with the large equilibrium warming it has sustained, and a cooler stratosphere consistent with its
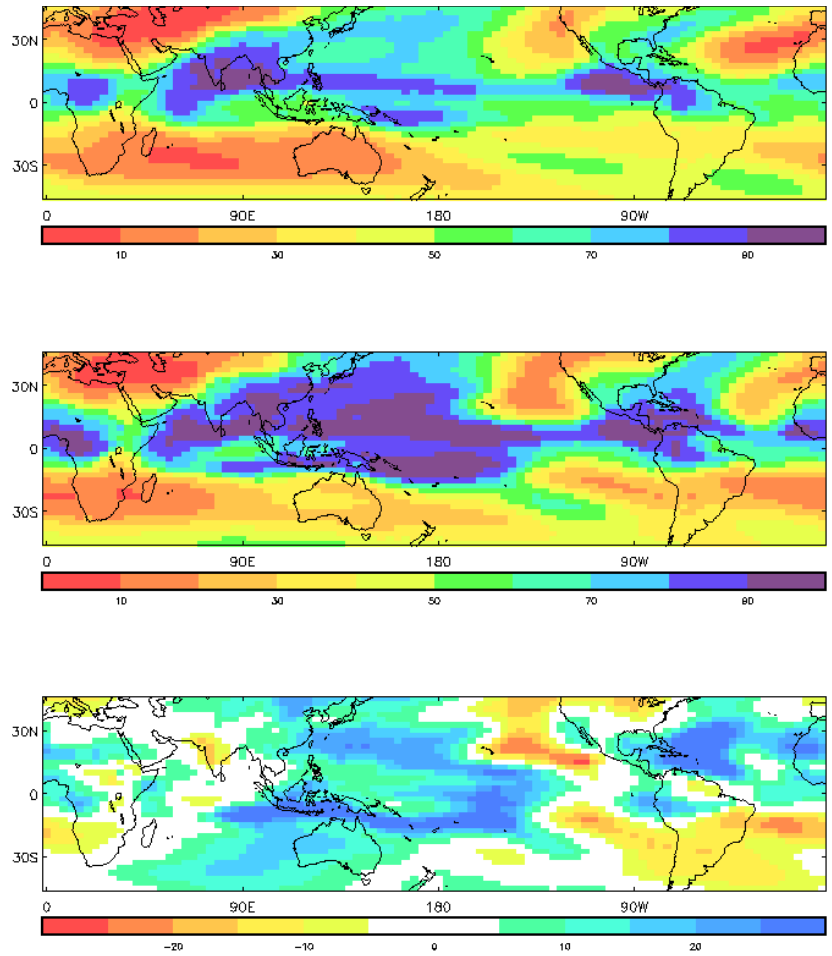

Fig. 3. Top panel: Relative Humidity (\%) averaged in all June, July and August months in STD1 at $200 \mathrm{hPa}$ (blue-green colours indicate largest values). Middle panel: as top panel but for LEP1. Bottom panel: as with top panel but for LEP1 minus STD1. Note the change in colour scale in the bottom panel.

much higher humidity. The differences between LEP1 and STD1 are shown in Fig. 2 (bottom): the difference between LEP1 and STD1 is 3 degrees at the tropopause level where the coldest temperatures are $197 \mathrm{~K}$ and $194 \mathrm{~K}$ respectively. Simple scaling by the Clausius-Clapeyron relationship would suggest that the difference in temperature between LEP1 and STD1 at the $100 \mathrm{hPa}$ level would cause SWV in LEP1 to be $60 \%$ greater than in LEP1 or about 3-4 ppmv. However, Fig. 1 shows that SWV in LEP1 is much higher than this, suggesting that tropical cold point temperature changes are not controlling the entry value of water vapour into the stratosphere in the "LEP"-integrations.

Greater light is shed on the mechanism by examining the seasonal variation of the stratospheric humidity anomaly. Figure 3 (top panel) shows that, in STD1, high values of upper tropospheric RH are evident where convection occurs in the Northern Indian and Eastern Pacific regions, but these high values are confined between $0^{\circ} \mathrm{N}$ and $25^{\circ} \mathrm{N}$. Figure 3 (middle panel) shows that in LEP1, high values of RH exist well into the Western Pacific north of $30^{\circ} \mathrm{N}$, which is where the tropopause drops to below the $200 \mathrm{hPa}$ level; this is shown clearly in the difference between LEP1 and STD1 (Fig. 3 bottom panel). 

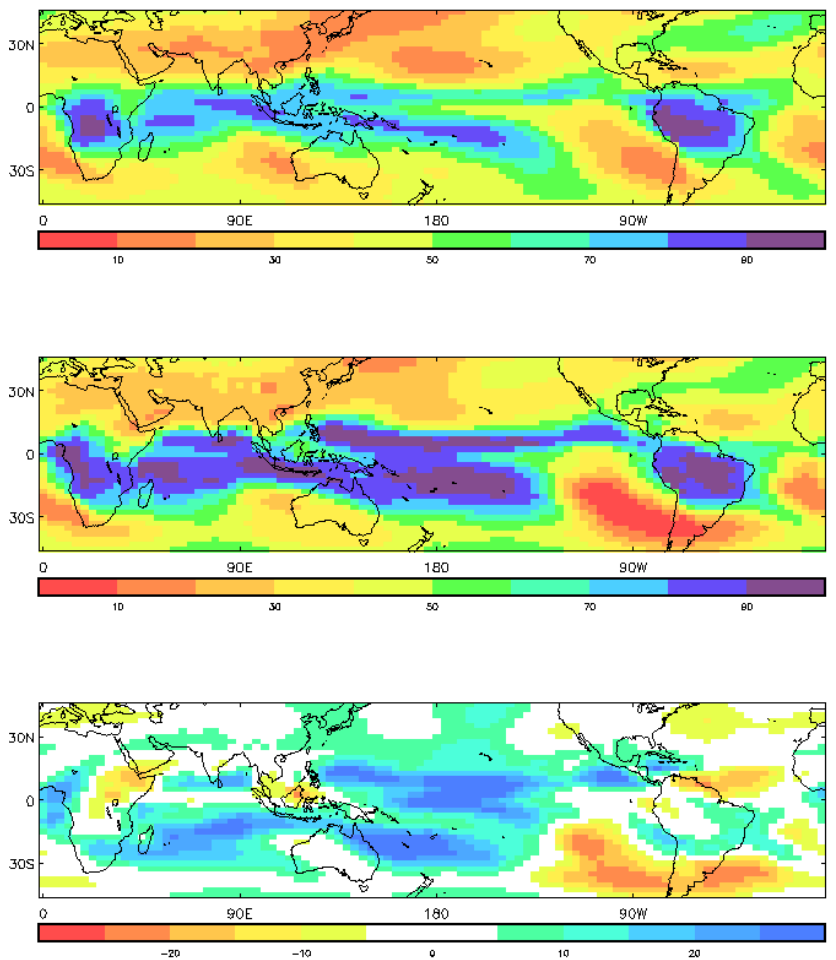

Fig. 4. As for Fig. 3 but for Relative Humidity averages in December, January and February at $200 \mathrm{hPa}$.

Figure 4 (top panel) shows that in DJF, high values of RH in STD1 are more zonally uniform, consistent with observations. Figure 4 (middle panel) shows that in LEP1, RH values are higher than in STD1 at this pressure level; however, these high values do not extend polewards of $30^{\circ}$ and Fig. 4 (bottom panel) confirms this. Together Figs. 3, 4 show that the JJA season is where most of the anomalously humid air in LEP1 is transported across the tropopause, which is consistent with the asymmetry in the annual averages shown in Fig. 1 (middle panel). The HadSM3 model has a very poorly resolved stratosphere - stratospheric levels lie at approximately $100,60,30,15$ and $5 \mathrm{hPa}$ - this is likely to allow upward diffusive transport of water vapour from the UTLS into the model's stratosphere.

Together, Figs. 1-4 appear to show that lower stratospheric humidity in the LEP run is not controlled by the coldest temperatures at the tropical tropopause, as is believed to be the case in the real atmosphere, and indeed as happens in STD1, but by summer subtropical/midlatitude temperature and humidity, especially in JJA. This effect is magnified in LEP2 because of higher upper tropospheric temperatures, leading to the very large values of SWV shown in Fig. 1 (bottom panel).

One can confirm the radiative importance of the water vapour in LEP1 by analysing the energy budget in terms of downward short-wave (SW) and long-wave (LW) radiation at the tropopause in runs STD1 and LEP1. The LW dif-

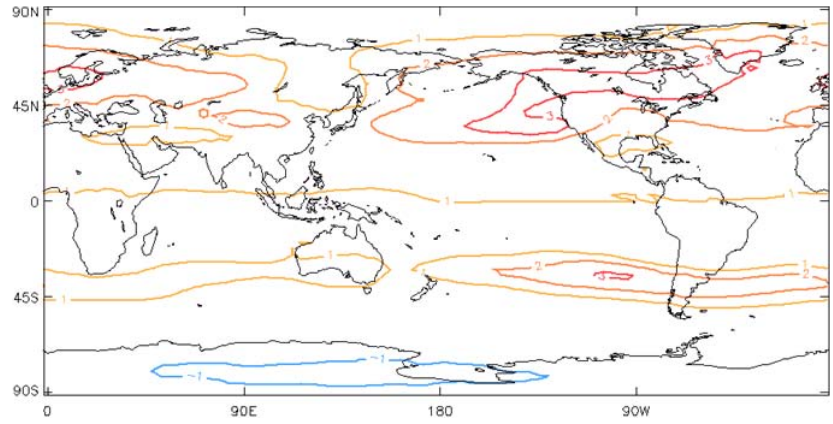

Fig. 5. The difference between the downward radiative fluxes across the tropopause in LEP1 and STD1 $\left(\mathrm{Wm}^{-2}\right)$ i.e. the impact of the low-entrainment parameter perturbation on the tropopause radiative balance. The contour interval is $1 \mathrm{Wm}^{-2}$.

ference is $+1.2 \mathrm{Wm}^{-2}$, whereas the $\mathrm{SW}$ difference is only $-0.1 \mathrm{Wm}^{-2}$, showing that $\mathrm{LW}$ effects arising from the difference in water vapour dominate the difference in downward radiation at the tropopause between STD1 and LEP1. The geographical pattern of the LW forcing difference is shown in Fig. 5. The largest differences occur in the northern subtropical regions rather than in the tropics, with northern hemisphere forcing differences being the larger; such a pattern is consistent with the difference in SWV between LEP1 and STD1 shown in Fig. 1 (middle panel).

The difference in downward LW flux at the tropopause between STD2 and STD1 at equilibrium is $0.6 \mathrm{Wm}^{-2}$, which can be largely attributed to the radiative effects of more $\mathrm{CO}_{2}$ in the stratosphere $\left(0.9 \mathrm{Wm}^{-2}\right.$ in HadSM3 $)$. There is no significant difference in downward SW flux. However, the difference in downward tropopause LW flux between LEP2 and LEP1 at equilibrium is $3.3 \mathrm{Wm}^{-2}$, while the difference in downward SW flux is $0.1 \mathrm{Wm}^{-2}$, suggesting that the extra stratospheric humidity (and cooling associated with the extra humidity) in LEP2 is contributing $2.8 \mathrm{Wm}^{-2}$ to the radiative budget after doubling $\mathrm{CO}_{2}$ compared to run STD2.

We have attempted to confirm that the extra radiative effect is associated with the extra SWV in LEP2 by three means. Firstly, Fig. 6 shows the timescale over which both the SWV anomaly and downward LW forcing at the tropopause build up. The solid curves in Fig. 6 (top) corresponding to STD1 and STD2 show negligible trends in SWV. However, run LEP2, shown by the dashed grey line, exhibits an increase in stratospheric humidity over the first 10 years of the integration. Note that the similar values of LEP1 and LEP2 in year 1 are slightly misleading, because LEP2 is started from the end of the STD2 integration: SWV at $60 \mathrm{hPa}$ simply spins up to 10 ppmv after a year. The dashed grey curve in Fig. 6 (bottom) shows how the downward LW flux at the tropopause evolves in response to the humidity anomaly in LEP2; it too increases over a timescale of 10 years until equilibrating at a value of $3.3 \mathrm{Wm}^{-2}$ above the LEP1 value, suggesting it is associated with the SWV anomaly. 

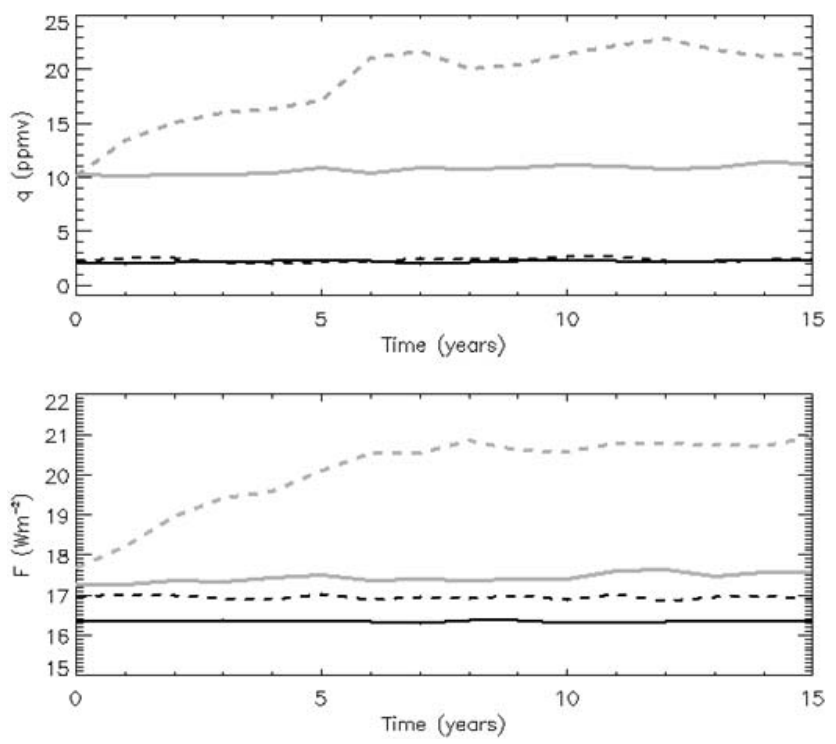

Fig. 6. Top panel: the evolution of globally averaged $60 \mathrm{hPa}$ specific humidity in time in STD1 (solid black); STD2 (dashed black); LEP1 (solid grey) and LEP2 (dashed grey). Bottom panel: line colours and styles as for the top panel but for the evolution of downward $\mathrm{LW}$ radiation at the tropopause in $\mathrm{Wm}^{-2}$.

As a second test of our hypothesis, we have calculated the radiative forcing at the tropopause resulting from a uniform change in SWV from $10 \mathrm{ppmv}$ to $20 \mathrm{ppmv}$ (the approximate mean SWV concentrations of the LEP1 and LEP2 integrations) using the fixed-dynamical-heating or FDH approach (e.g.: Forster and Shine, 2002). The FDH method employs a radiative model (in this case the HadSM3 radiative code) and an equilibrium HadSM3 temperature field to calculate a radiative heating rate which is assumed to be equal and opposite to the dynamical heating rate $X(\mathrm{y}, \mathrm{z})$. The stratosphere is then perturbed radiatively and the forcing and temperature change above the tropopause calculated assuming $X$ does not change. The FDH forcing is $2.77 \mathrm{Wm}^{-2}$, which is very close to the $2.8 \mathrm{Wm}^{-2}$ additional downward LW flux at the tropopause between LEP2 and LEP1 compared to STD1 and STD2. This shows that the extra SWV in LEP2 is capable of explaining a large component of the extra downward LW forcing in that run.

Finally, we have estimated what the climate sensitivity would be for the STD and LEP experiments if their clearsky and cloud feedback parameters were interchanged. We diagnose these feedback parameters following the method of Webb et al. (2006) and define the total feedback $\left(\mathrm{Wm}^{-2}\right)$ to be $\Lambda=\left(R^{\prime}-f\right) / T^{\prime}$ where $f$ is the radiative forcing $\left(\mathrm{Wm}^{-2}\right)$, $T$ ' is the climate sensitivity and $R^{\prime}$ is the difference in the net downward radiative flux at the top of the atmosphere between the control and $2 \times \mathrm{CO}_{2}$ simulation (which is zero at equilibrium). This can be decomposed into clear-sky atmosphere and cloud components, $\Lambda=\Lambda_{\mathrm{A}}+\Lambda_{\mathrm{C}}$, where
$\Lambda_{\mathrm{A}}=\left(R_{\mathrm{A}}{ }^{\prime}-f\right) / T^{\prime}$ and $\Lambda_{\mathrm{C}}=\left(R^{\prime}-R_{\mathrm{A}}{ }^{\prime}\right) / T^{\prime}, R_{\mathrm{A}}{ }^{\prime}$ being the change in the net downward clear-sky radiative flux at the top of the atmosphere at equilibrium. Assuming a standard HadCM3 value for net $\mathrm{CO}_{2}$ forcing of $3.75 \mathrm{Wm}^{-2}$ for both experiments, the clear-sky feedback parameters $\Lambda_{\mathrm{A}}$ for STD and LEP are -1.33 and $-0.79 \mathrm{Wm}^{-2} \mathrm{~K}^{-1}$ respectively, while the cloud feedback parameters $\Lambda_{\mathrm{C}}$ are 0.21 and $0.24 \mathrm{Wm}^{-2} \mathrm{~K}^{-1}$. The climate sensitivities are 3.3 and $6.8 \mathrm{~K}$ for STD and LEP respectively. By rearranging the equations above, we can estimate the climate sensitivity expected for a given combination of clear-sky and cloud feedback parameters, $T^{\prime}=\left(R^{\prime}-f\right) /\left(\Lambda_{\mathrm{A}}+\Lambda_{\mathrm{C}}\right)$. The STD clear-sky feedback combined with the LEP cloud feedback yields a climate sensitivity of $3.4 \mathrm{~K}$, while the LEP clear-sky feedback combined with the STD cloud feedback yields $6.5 \mathrm{~K}$. Hence the difference in the clear-sky feedback between the STD and LEP experiments explains $95 \%$ of the difference in their climate sensitivities.

\section{Discussion}

The radiative forcing associated with doubling $\mathrm{CO}_{2}$ from pre-industrial concentrations (in HadCM3) is $3.75 \mathrm{Wm}^{-2}$. If the extra downward LW effect associated with SWV in the LEP2 experiment is $2.8 \mathrm{Wm}^{-2}$, this will almost double the total radiative forcing. The effects of the extra SWV therefore explain the high sensitivity of the LEP1/2 model incarnation. Our results suggest that the tropospheric feedbacks in LEP1/2 are similar to other members of the Murphy et al. (2004) ensemble, all of which have a much lower temperature response.

One can answer the question of whether the stratospheric water vapour response in LEP2 is an indirect forcing or a feedback (the latter being dependent on surface change) by plotting the evolution of the temperature at $1.5 \mathrm{~m}$ vs. the topof-atmosphere (hence TOA) net flux in run LEP2 in the manner of Gregory et al. (2004). In their analysis, points lie along more or less a straight line with a negative gradient as the temperature warms and the net TOA flux reduces to zero. Figure 7 shows that in the first 5-10 years of model integration when the SWV is increasing in LEP2 (Fig. 6), TOA flux actually increases before decreasing in line with Gregory et al. (2004). Note again that the global mean temperature anomaly in year 1 is $3 \mathrm{~K}$, since LEP2 was started from a STD2 initial state, not a LEP1 control state. The initial increase implies that the SWV response is neither a rapid forcing (happening on timescales of months like stratospheric adjustment to $\mathrm{CO}_{2}$ doubling) nor a simple feedback which responds linearly with temperature, but an extra response to the warming with its own additional response timescale.

Various methods have been used to assess the likelihood of the climate system's sensitivity mirroring the magnitude of the LEP1/2 system; some have been based on comparing the climatology of individual ensemble members with 


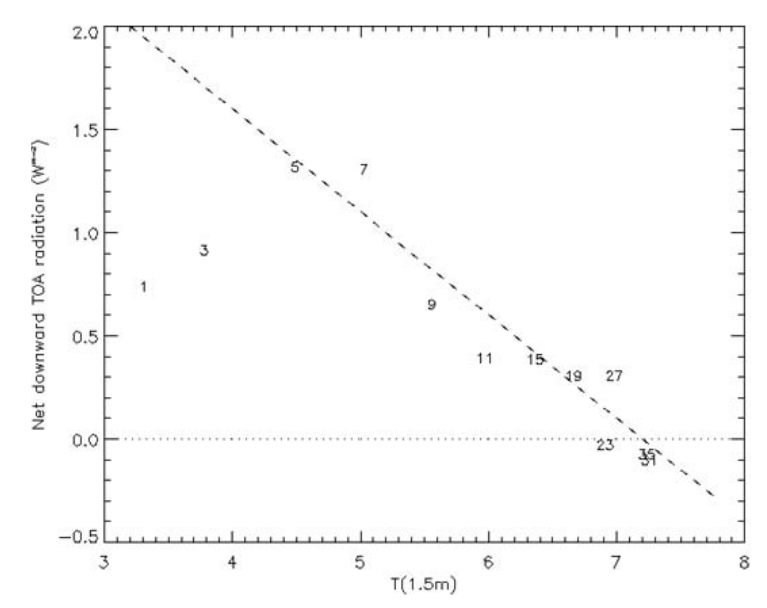

Fig. 7. Anomalous net top-of-atmosphere downward flux in LEP2 vs surface temperature change during the transient-warming phase of the integration. (Each value has had the time-mean value for that quantity in run LEP1 subtracted from it.) The numbers identify the years into the integration. Years 1-10 have biannual means plotted, while years 10-35 have quadrennial means plotted. The dashed line corresponds to the linear regression $T O A=3.6-0.5 T$ and the slope represents the feedback parameter.

time-averaged observations (Murphy et al., 2004; Collins et al., 2010), some exploit the observed evolution of global mean temperature (Gregory et al., 2002) while others use novel tests using different numerical weather prediction models (Rodwell and Palmer, 2006). The key difference in the present work is that the process causing the large stratospheric humidity bias in LEP1 appears to be the same process that is responsible for the water vapour increase, and hence the large temperature response, in LEP2. There is therefore a stronger case for considering the temperature response in LEP2 to be implausible.

A scenario that should be considered is whether the high temperature response in LEP2 might occur in reality because of a real change in convective entrainment or other processes that significantly increase SWV in a warmer climate. There has indeed been an increasing trend in stratospheric humidity over the latter half of the 20th century, which is thought to be climatically significant (Forster and Shine, 2002; Solomon et al., 2010). However, the trend is noisy (e.g.: Rosenlof et al., 2001), has many possible causes not related to climate warming (e.g.: Scaife et al., 2003; Joshi and Shine, 2003), and at present is hard to attribute (Fueglistaler and Haynes, 2005). In addition, stratospheric water vapour values decreased from the late 1990s to the early 2000s and there is no evidence of a positive trend since the year 2000 (Randel et al., 2006).

Since LEP2 exhibits a radiative effect from the change in SWV that is about $80 \%$ of the $\mathrm{CO}_{2}$ forcing, one might expect that the radiative forcing associated with observed SWV changes since pre-industrial times should be a significant fraction of the $1.6 \mathrm{Wm}^{-2}$ associated with $\mathrm{CO}_{2}$ since 1860 ,

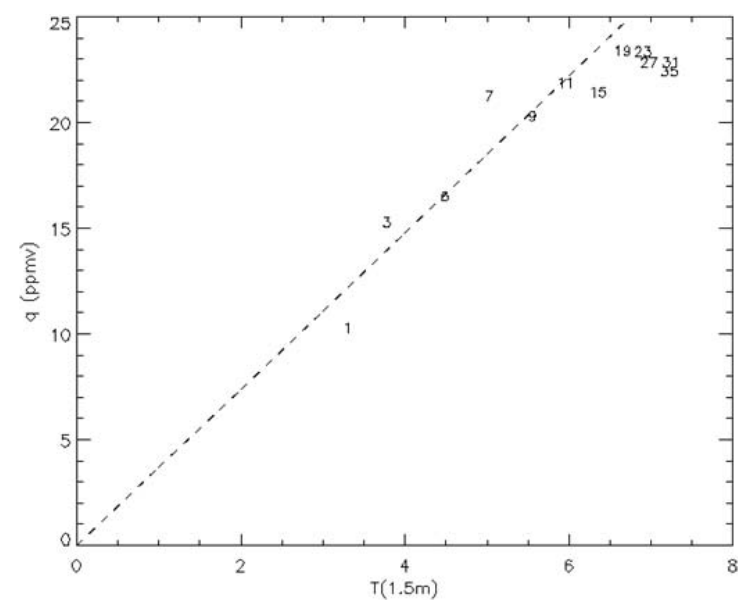

Fig. 8. Stratospheric Water Vapour at $60 \mathrm{hPa}$ in LEP2 vs surface temperature during the transient-warming phase of the integration. The temperature values have had the time-mean value in run LEP1 subtracted from them (as in Fig. 7). The dashed line corresponds to the linear regression $Y=3.75 T$.

if the real world behaved like LEP. Forster and Shine (2002) estimated a value of only $0.29 \mathrm{Wm}^{-2}$ for stratospheric water forcing in the 20th century, and this was based on the peak trend, which has now lessened.

Figure 8 shows the sensitivity of SWV at $60 \mathrm{hPa}$ to $1.5 \mathrm{~m}$ temperature in the LEP2 run. The gradient is approximately $3.7 \mathrm{ppmv} / \mathrm{K}$ during the transient phase; if such a feedback had happened in the 20th century, when globally averaged temperatures rose by $0.8 \mathrm{~K}$, SWV should have increased by almost 3 ppmv, which is much higher than the observed trend (see above and Rosenlof et al., 2001). We conclude that it is therefore very unlikely that the observed trend in SWV is consistent with the LEP1/LEP2 integrations, although some SWV feedback of this nature, albeit having a much smaller magnitude, might operate under enhanced levels of $\mathrm{CO}_{2}$. Further work is required on this topic.

Future research in this area should involve examining the response of the HadSM3 model when multiple parameters are perturbed at the same time, given the known interaction of the low entrainment parameter with other perturbations (Rougier et al., 2009). The robustness of our results to multiple parameter perturbations could also be quantified in this way. For example, Rougier et al. (2009) show that relatively large values of climate sensitivity are possible in HadSM3 for much more reasonable values of the entrainment parameter.

\section{Conclusions}

We have investigated the "low-entrainment-value" parameter pre-industrial and $2 \times \mathrm{CO}_{2}$ climates of the HadSM3 ensemble. We find that the high sensitivity of this climate is due to a large increase in stratospheric water vapour in the $2 \times \mathrm{CO}_{2}$ 
integration. Given that this is a result of a process that also causes a very large bias in the stratospheric humidity in the present-day climate, it is very unlikely that the real climate system has a sensitivity this high for this reason.

This analysis has again shown that changes to minor constituents in the stratosphere can have profound effects on the evolution of the surface climate in models. Any future metrics of model behaviour should take account of potential biases arising from this region of the atmosphere, especially if the stratosphere is poorly resolved as is the case in HadSM3.

Acknowledgements. Manoj Joshi is supported by NCAS Climate, Mark Webb is supported by the Joint DECC and Defra Integrated Climate Programme, DECC/Defra (GA01101), and Amanda Maycock is supported by a NERC PhD studentship, supplemented by a Met office CASE award. This work was undertaken while Mat Collins was also supported by the Met Office DECC/Defra contract. We would like to thank David Karoly, William Ingram, and Jonathan Gregory for comments, and the Met Office Hadley Centre QUMP team for model output.

Edited by: P. Haynes

\section{References}

Collins, M., Booth, B. B. B., Bhaskaran, B., Harris, G., Murphy, J. M., Sexton, D. M. H., and Webb, M. J.: A comparison of perturbed physics and multi-model ensembles: Model errors, feedbacks and forcings, Clim. Dynam., in press, 2010.

Dessler, A. E. and Sherwood, S. C.: Effect of convection on the summertime extratropical lower stratosphere, J. Geophys. Res., 109, D23301, doi:10.1029/2004JD005209, 2004.

Forster, P. M. De F. and Shine, K. P.: Assessing the climate impact of trends in stratospheric water vapor, Geophys. Res. Lett., 29, 6, doi:10.1029/2001GL013909, 2002.

Fueglistaler, S. and Haynes, P. H.: Control of interannual and longer-term variability of stratospheric water vapor, J. Geophys. Res., 110, D24108, doi:10.1029/2005JD006019, 2005.

Gregory, J. M., Stouffer, R., Raper, S., Rayner, N., and Stott, P. A.: An observationally-based estimate of the climate sensitivity, J. Climate., 15, 3117-3121, 2002.

Gregory, J. M., Ingram, W. J., Palmer, M. A., Jones, G. S., Stott, P. A., Thorpe, R. B., Lowe, J. A., Johns, T. C., and Williams, K. D.: A new method for diagnosing radiative forcing and climate sensitivity, Geophys. Res. Lett., 31, L03205, doi:10.1029/2003GL018747, 2004.

IPCC, Climate Change 2007: The Physical Science Basis, Contribution of Working Group I to the Fourth Assessment Report of the Intergovernmental Panel on Climate Change, edited by: Solomon, S., Qin, D., Manning, M., Chen, Z., Marquis, M., Averyt, K. B., Tignor, M., and Miller, H. L., Cambridge University Press, Cambridge, United Kingdom and New York, NY, USA, 2007.

Joshi, M. M. and Shine, K. P. : A GCM study of volcanic eruptions as a cause of increased stratospheric water vapour, J. Climate, 16, 3525-3534, 2003.
Meehl, G. A., Stocker, T. F., Collins, W. D., Friedlingstein, P., Gaye, A. T., Gregory, J. M., Kitoh, A., Knutti, R., Murphy, J. M., Noda, A., Raper, S. C. B., Watterson, I. G., Weaver, A. J., and Zhao, Z.-C.: Global Climate Projections, in: Climate Change 2007: The Physical Science Basis. Contribution of Working Group I to the Fourth Assessment Report of the Intergovernmental Panel on Climate Change, edited by: Solomon, S., Qin, D., Manning, M., Chen, Z., Marquis, M., Averyt, K. B., Tignor, M., and Miller, H. L., Cambridge University Press, Cambridge, United Kingdom and New York, NY, USA, 2007.

Murphy, J. M., Sexton, D. M. H., Barnett, D. N., Jones, G. S., Webb, M. J., and Collins, M.: Quantification of modelling uncertainties in a large ensemble of climate change simulations, Nature, 430, 768-772, 2004.

Randel, W. J., Wu, F., Vömel, H., Nedoluha, G. E., and Forster, P.: Decreases in stratospheric water vapor after 2001: Links to changes in the tropical tropopause and the Brewer-Dobson circulation, J. Geophys. Res., 111, D12312, doi:10.1029/2005JD006744, 2006.

Rodwell, M. J. and Palmer, T. N.: Using numerical weather prediction to assess climate models, Q. J. Roy. Meteor. Soc., 133, 129-146, 2006.

Rosenlof, K. H., Oltmans, S. J., Kley, D., Russell III, J. M., Chiou, E.-W., et al.: Stratospheric water vapor increases over the past half-century, Geophys. Res. Lett., 28, 1195-1198, 2001.

Rougier, J. C., Sexton, D. M. H., Murphy, J. M., and Stainforth, D.: Analysing the climate sensitivity of the HadSM3 climate model using ensembles from different but related experiments, J. Climate, 22, 3540-3557, doi:10.1175/2008JCLI2533.1, 2009.

Sanderson, B. M., Piani, C., Ingram, W. J., Stone, D. A., and Allen, M. R.: Towards constraining climate sensitivity by linear analysis of feedback patterns in thousands of perturbed-physics GCM simulations, Clim. Dynam., 30, 175-190, 2008.

Scaife, A. A., Butchart, N., Jackson, D. R., and Swinbank, R.: Can changes in ENSO activity help to explain increasing stratospheric water vapor?, Geophys. Res. Lett., 30, 1880, doi:10.1029/2003GL017591, 2003.

Solomon, S., Rosenlof, K. H., Portmann, R. W., Daniel, J. S., Davis, S. M., Sanford, T. J., and Plattner, G.-K.: Ontributions of Stratospheric Water Vapor to Decadal Changes in the Rate of Global Warming, Science, 327, 1219-1223, 2010.

Stainforth, D. A., Aina, T., Christensen, C., Collins, M., Faull, N., Frame, D. J., Kettleborough, J. A., Knight, S., Martin, A., Murphy, J. M., Piani, C., Sexton, D., Smith, L. A., Spicer, R. A., Thorpe, A. J., and Allen, M. R.: Uncertainty in predictions of the climate response to rising levels of greenhouse gases, Nature, 433, 403-406, 2005.

Webb, M. J., Senior, C. A., Sexton, D. M. H., Ingram, W. J., Williams, K. D., Ringer, M. A., McAvaney, B. J., Colman, R., Soden, B. J., Gudgel, R., Knutson, T., Emori, S., Ogura, T., Tsushima, Y., Andronova, N., Li, B., Musat, I., Bony, S., and Taylor, K. E.: On the contribution of local feedback mechanisms to the range of climate sensitivity in two GCM ensembles, Clim. Dynam., 27, 17-38, doi:10.1007/s00382-006-0111-2, 2006. 